Retraction

\title{
Retracted: Comparison of Microstructure and Mechanical Properties of A356/SiC Metal Matrix Composites Produced by Two Different Melting Routes
}

\author{
International Journal of Manufacturing Engineering
}

Received 9 April 2015; Accepted 9 April 2015

Copyright (C) 2015 International Journal of Manufacturing Engineering. This is an open access article distributed under the Creative Commons Attribution License, which permits unrestricted use, distribution, and reproduction in any medium, provided the original work is properly cited.

\begin{abstract}
The paper titled "Comparison of Microstructure and Mechanical Properties of A356/SiC Metal Matrix Composites Produced by Two Different Melting Routes" [1] has been retracted as it contains figures that are substantially similar to figures in the following published papers: "Microstructure and Mechanical Properties of A356/SiC Composites Fabricated by Electromagnetic Stir Casting" by Shashi Prakash Dwivedi, Satpal Sharma, and Raghvendra Kumar Mishra and "Effects of Roller Burnishing Process Parameters on Surface Roughness of A356/5\% SiC Composite Using Response Surface Methodology" by Shashi Prakash Dwivedi, Satpal Sharma, and Raghvendra Kumar Mishra.
\end{abstract}

\section{References}

[1] S. P. Dwivedi, S. Sharma, and R. K. Mishra, "Comparison of microstructure and mechanical properties of $\mathrm{A} 356 / \mathrm{SiC}$ metal matrix composites produced by two different melting routes," International Journal of Manufacturing Engineering, vol. 2014, Article ID 747865, 13 pages, 2014. 

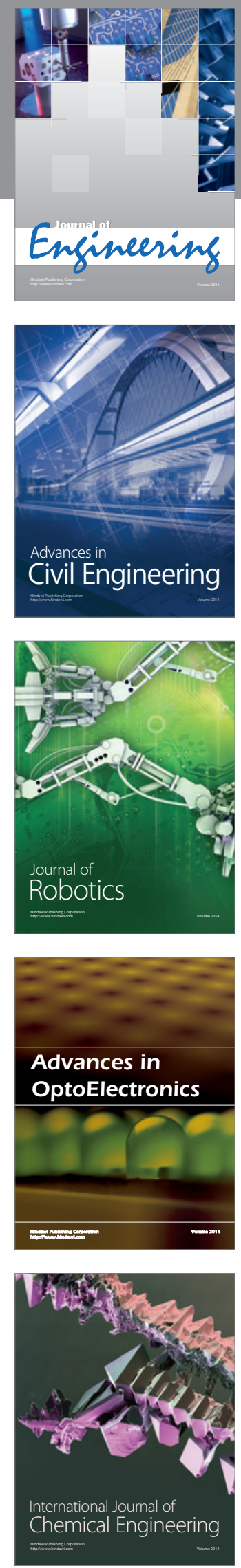

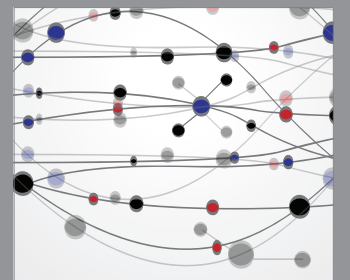

The Scientific World Journal
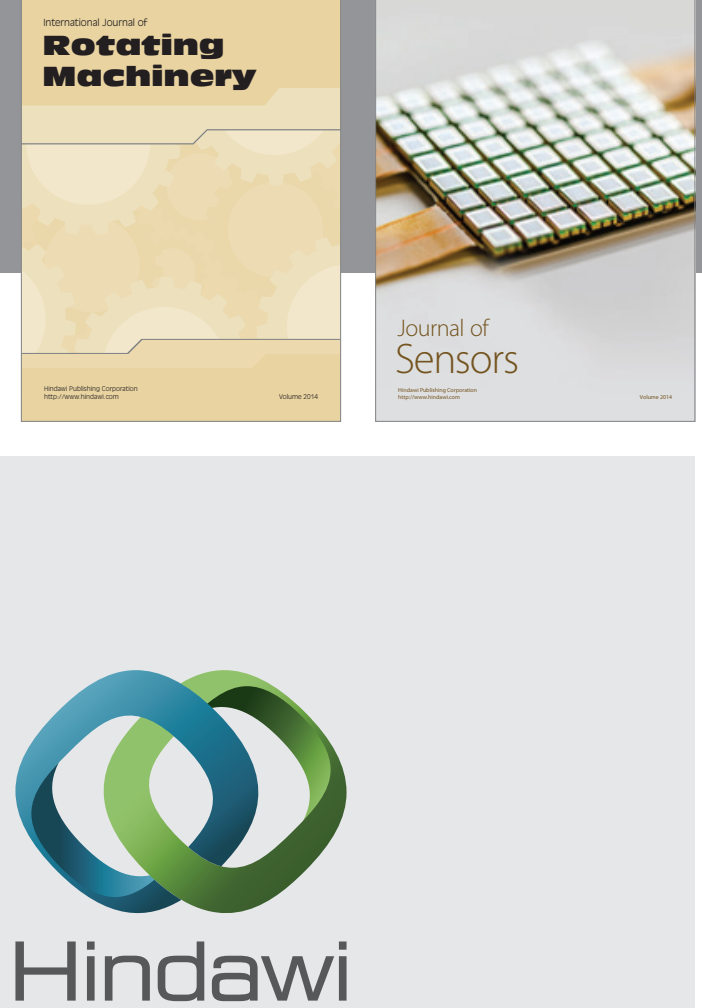

Submit your manuscripts at http://www.hindawi.com
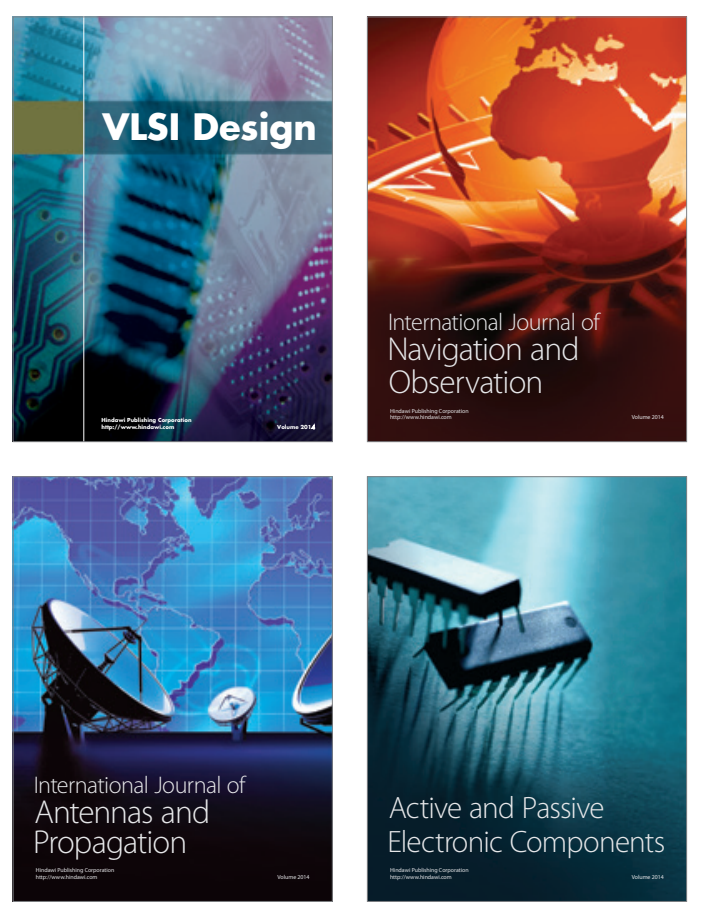
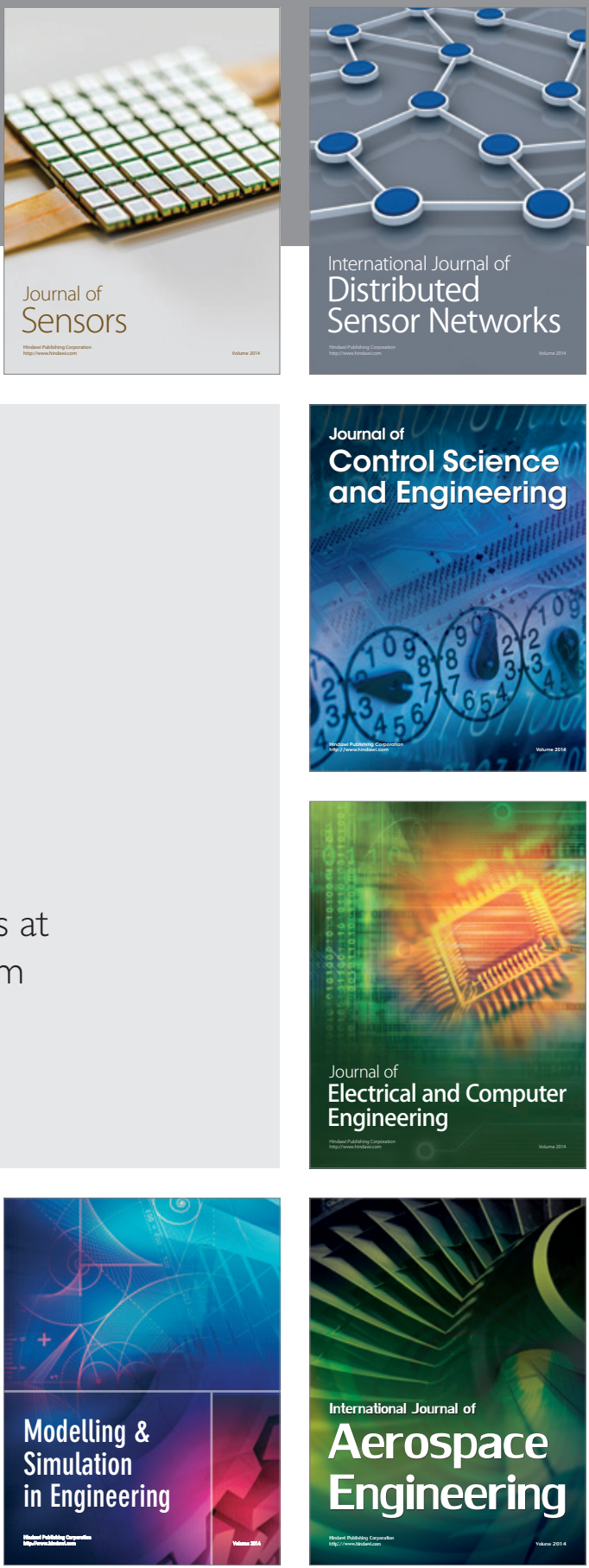

Journal of

Control Science

and Engineering
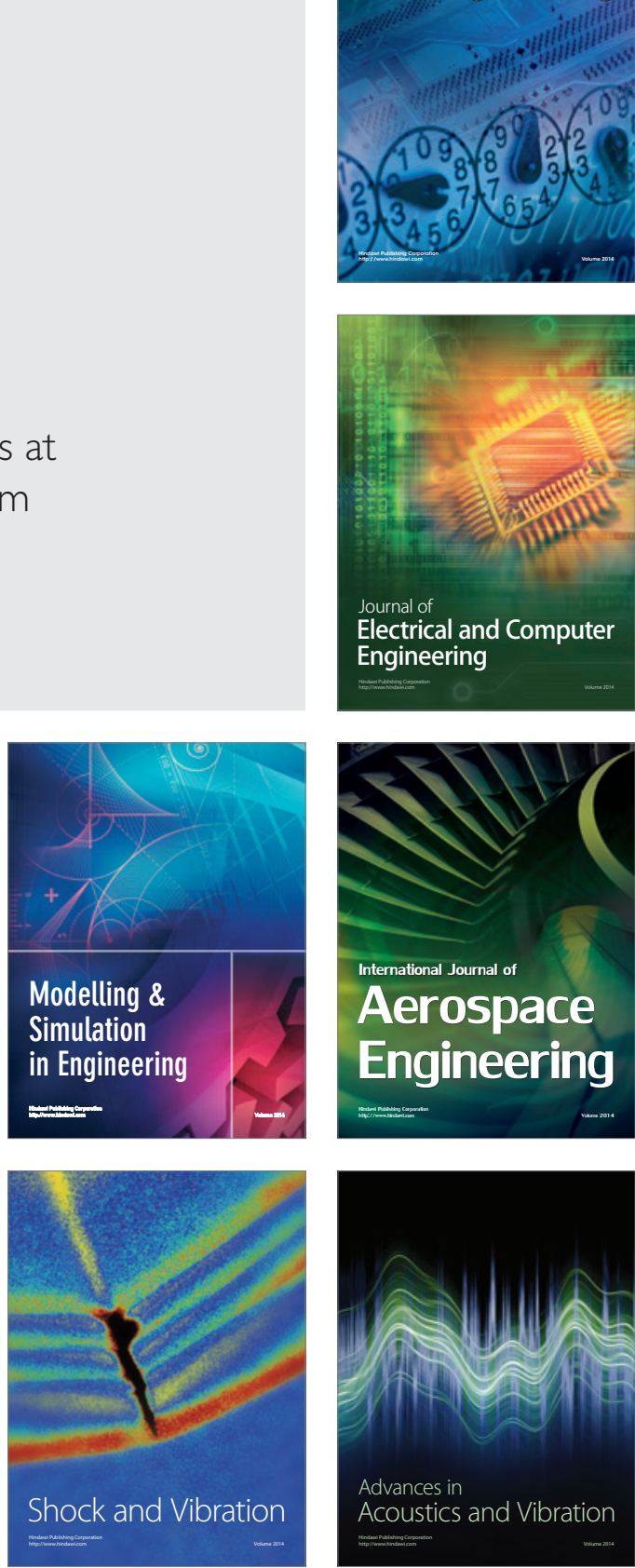